\title{
Spatial Variation of Soot Volume Fractions in Pool Fire Diffusion Flames
}

\author{
S. BARD and P. J. PAGNI
}

Mechanical Engineering Department

University of California

Berkeley, California 94720, USA

\section{ABSTRACT}

Measurements are reported of the line of sight averaged soot volume fraction as a function of height within pool fire flames fueled by polystyrene (PS) and polymethylmethacrylate (PMMA). No-lip pools with diameters of $7.5 \mathrm{~cm}$ and $15 \mathrm{~cm}$ were examined and compared with Markstein's results at $31 \mathrm{~cm}$ and 73 $\mathrm{cm}$. The multi-wavelength laser transmission technique used has been previously described. PS and PMMA represent two distinct cases. For the optically thick PS the soot volume fraction, $f_{y}$, appears to be independent of fuel scale at $3.3 \mathrm{ppm}$. For the optically thin PMMA, fv increases substantially with fuel scale from $\sim 0.2$ to $\sim 0.7 \mathrm{ppm}$. For both fuels, $f_{v}$ decreases only slightly with height and is well approximated as uniform throughout the flame. The correlation, $f_{v} / f_{v_{\max }}=1.5(k L)^{0.33}$ for $k L \leqslant 0.3$ and $=1$ for $k L \geqslant 0.3$, where $k L$ is the flame optical thickness, is inferred from this scant data base. It may provide $f_{V}$ for any fuel at any scale as well as estimates of the maximum possible conversion of fuel carbon to soot.

\section{INTRODUCTION}

It is well established that flame radiation is a dominant mechanism for fire growth $[1,2]$ and that carbon particles within the flame produce most of the radiation $[3,4]$. Since these particles are small compared to the infrared wavelengths emitted, the flame volume fraction occupied by soot, $f_{v}$, is the characteristic most important to flame radiation $[5,6]$.

Neglecting blockage effects, the radiative energy flux from each element of flame surface area can be approximated as

$\dot{q}^{\prime \prime}=\varepsilon_{f} \sigma \mathrm{T}_{f}^{4}$,

where $T_{f}$ is a mean flame temperature and the flame emissivity is

$\varepsilon_{f}=\varepsilon+\varepsilon_{g}-\varepsilon \varepsilon_{g}$.

Supported by the Center for Fire Research under USDOC-NBS Grant No. 60NAND5D0552. Valuable assistance from J. de Ris, M. Brosmer and J. Reed is gratefully acknowledged. 
The gas emissivity, $\varepsilon_{g}$ is small, usually less than $20 \%$ of $\varepsilon_{f}[1]$. Standard techniques $[7,8]$ are available to evaluate $\varepsilon_{\mathrm{g}}$ in terms of the $\mathrm{H}_{2} \mathrm{O}$ and $\mathrm{CO}_{2}$ partial pressures and the flame mean beam length, $L,[9,10]$. The soot emissivity is given [5] by

$\varepsilon=1-\exp (-k L)$,

where the soot absorption coefficient is defined as

$k=36 \pi F_{a}(\bar{\lambda}) f_{v} / \bar{\lambda}$,

with the mean emitted wavelength,

$\bar{\lambda} T_{f}=0.40 \mathrm{~cm}{ }^{\circ} \mathrm{K}$.

Orloff and de Ris [9] suggest $T_{f} \approx 1200^{\circ} \mathrm{K}$ for most pool fires; Eq. (5) then gives $\bar{\lambda}=3.3 \mu \mathrm{m}$. The soot optical property effects are all in $\mathrm{F}_{\mathrm{a}}(3.3) \approx 0.044$ [11]. The only remaining unknown needed to quantify flame radiation is $f_{v}$. Since no fundamental theory of soot formation is yet available, experimental soot volume fractions are needed. Several techniques exist for measuring $f_{v}$ $[3,6,12-16]$, one of which is described in the next section. Empirical answers to the following two questions are sought here: How does $f_{v}$ vary within the pool fire? and How does $f_{v}$ scale with pool fire size?

\section{EXPERIMENT}

The experimental procedure has been described $[3,6]$. Here $7.5 \mathrm{~cm}$ and $15 \mathrm{~cm}$ diameter pools formed of beads of polystrene, PS and polymethylmethacrylate, PMMA, with no lip [9] were scanned with height using the apparatus shown in Fig. 1. For each fuel 100 instantaneous intensity measurements at several wavelengths were stored and correlated with simultaneous laser pathlengths measured separately for each data point. The pathlength, $\ell$, was taken as the

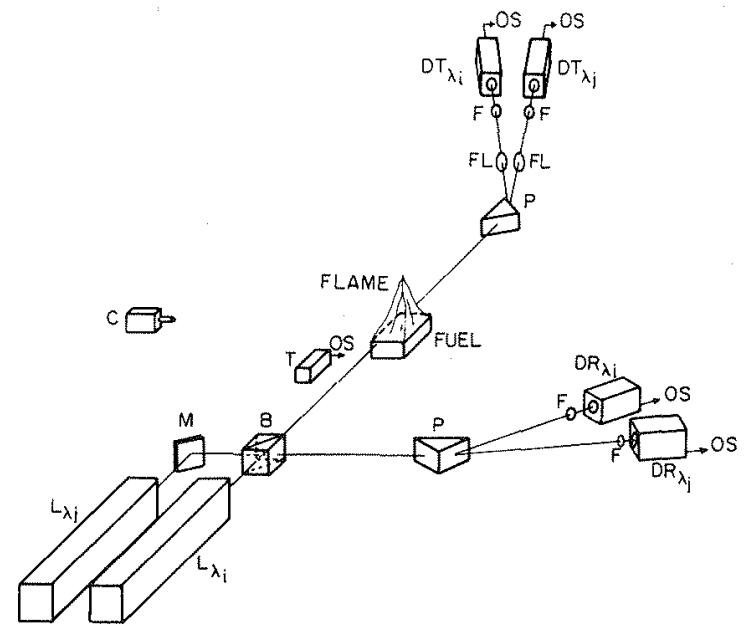

Fig. 1. Schematic of the multi-wavelength extinction apparatus. Shown are the lasers ( $L)$, mirror $(M)$, beamsplitter $(B)$, prism $(P)$, timer $(T)$, camera $(C)$, detectors (D), focusing lens (FL), filters (F) and output signals (OS). 
width of continous luminosity in a timed videotape frame. When the laser beam passes through the flame, the transmitted intensity, I, is related to the initial intensity, $I_{0}$, by

$$
I(\lambda) / I_{0}(\lambda)=\exp (-\tau(\lambda) \ell) \text {. }
$$

The intensity and pathlength data $I, I_{0}$, and $l$ give experimental extinction coefficients, $\tau(\lambda)$. Results at each of two wavelengths give effectively two equations in two unknowns, the two parameters in the size distribution, $N(r)$, listed below. Since $\tau$ is not homogeneous along the pathlength, a line of sight average extinction coefficient and average soot volume fraction, are obtained here. If the radial variations in $f_{y}$ are important, local measurements are required [13]. From the viewpoint of calculating fiame radiation, these averages contain the desired information.

The extinction coefficient is related to the Mie extinction efficiency, $Q(\lambda, m, r)$, of each particle of radius $r$, and to the particle concentration, $N(r) d r$, by

$\tau(\lambda, m, r)=\int_{0}^{\infty} N(r) Q(\lambda, m, r) \pi r^{2} d r$

where $m$ is the soot complex index of refraction [11]. Previous studies [6,17] suggest a Gamma size distribution with the constraint of a specified ratio of standard deviation to mean particle radius, $\sigma / r_{\mathrm{m}}=1 / 2$. In terms of the most probable radius, $r_{\max }$, and the total particle concentration, $N_{0}$, the distribution is

$N(r) / N_{0}=\left(27 r^{3} / 2 r_{\max }{ }^{4}\right) \exp \left(-3 r / r_{\max }\right)$.

(See Fig. 2.) Once $N_{0}$ and $r_{\max }$ are known from the extinction measurements, the soot volume fraction is

$f_{v} \equiv \frac{4}{3} \pi \int_{0}^{\infty} N(r) r^{3} d r=\frac{54}{38} \pi \Gamma(7) N_{0} r_{\max }^{3} \approx 18.62 N_{0} r_{\max }^{3}$.

The results are summarized in Table $I$. The observed variation of $r_{\max }, N_{0}$ and $f_{v}$ with height within the flame is as expected. The particle radii increase moderately while the concentrations decrease, due to coagulation and oxidation. The net effect of these complimentary variations is that the soot volume fraction decreases only slightly. Multi-wavelength results show $f_{v}$ is determined more accurately than either $r_{\max }$ or $N_{0}[6,15]$. The evolution of the particle size distribution is approximated by Fig. 2 for the $15 \mathrm{~cm}$ diameter PMMA pool fire. The change in $f_{v}$ is sufficiently small, that to a first approximation, $f_{v}$ is uniform throughout the flame. Markstein's results at larger scale [12,18] confirm this conclusion when corrected for optical properties and gas species contributions [19].

The soot absorption coefficient in column 5 of Table I comes from the $f_{V}$ of column 4 in Eqs. ( 4 and 5 ) with $T_{f} \sim 1200^{\circ} \mathrm{K}$ and $F_{a} \sim 0.044$. The soot emissivity in the last column is obtained from Eq. (3) with $\mathrm{k}$ and a mean beam length appropriate to the entire flame. The literature contains expressions for the flame height $[12,20]$ and shape $[9,10,21]$ which can be used to calculate $L$ from

$L=3.6 V_{f} / A_{f}$, 


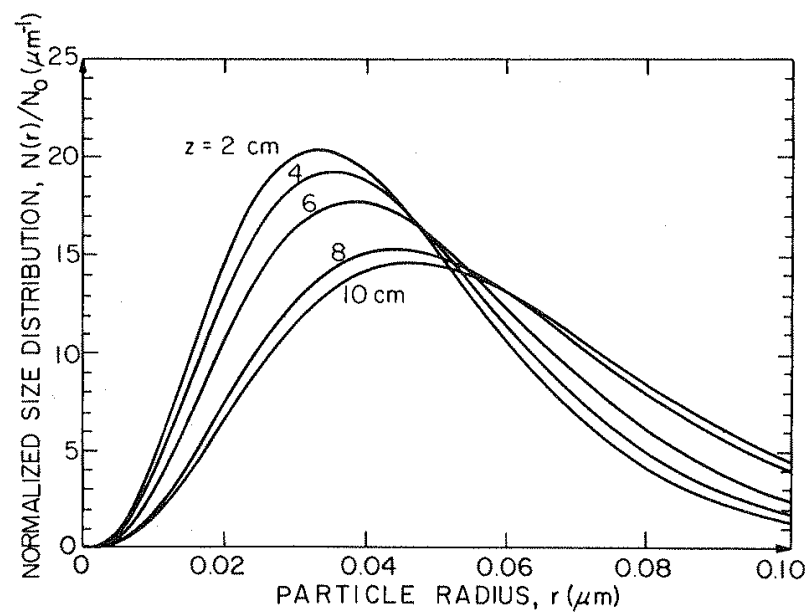

Fig. 2. Evolution of flame particulate size distribution with increasing height, $z$, for a $15 \mathrm{~cm}$ diameter PMMA pool fire.

TABLE I. Experimental Results

\begin{tabular}{|c|c|c|c|c|c|c|}
\hline Fuel $/ \mathrm{D}, \mathrm{cm}$ & $\mathrm{cm}$ & $\begin{array}{c}r_{\max } \\
\mathrm{nm}\end{array}$ & $\begin{array}{c}N_{0} \times 10^{-9} \\
\mathrm{~cm}^{-3}\end{array}$ & $\begin{array}{l}f_{V} \\
p p m\end{array}$ & $\stackrel{k}{m^{-1}}$ & $\varepsilon$ \\
\hline$P S / 7.5$ & $\begin{array}{l}2 \\
3 \\
4 \\
5\end{array}$ & $\begin{array}{l}34 \\
35 \\
37 \\
38\end{array}$ & $\begin{array}{l}5.3 \\
4.1 \\
3.4 \\
3.0\end{array}$ & $\begin{array}{l}3.9 \\
3.3 \\
3.2 \\
3.1\end{array}$ & $\begin{array}{l}6.1 \\
5.2 \\
5.0 \\
4.9\end{array}$ & $\begin{array}{l}0.20 \\
0.18 \\
0.17 \\
0.17\end{array}$ \\
\hline PS/15 & $\begin{array}{r}2 \\
4 \\
6 \\
8 \\
10\end{array}$ & $\begin{array}{l}33 \\
35 \\
40 \\
42 \\
42\end{array}$ & $\begin{array}{l}5.4 \\
4.2 \\
2.6 \\
2.0 \\
2.1\end{array}$ & $\begin{array}{l}3.6 \\
3.4 \\
3.1 \\
2.8 \\
2.9\end{array}$ & $\begin{array}{l}5.7 \\
5.3 \\
4.9 \\
4.4 \\
4.6\end{array}$ & $\begin{array}{l}0.34 \\
0.33 \\
0.31 \\
0.28 \\
0.29\end{array}$ \\
\hline PMMA/ 7.5 & $\begin{array}{l}2 \\
3 \\
4 \\
5\end{array}$ & $\begin{array}{l}42 \\
43 \\
45 \\
46\end{array}$ & $\begin{array}{l}0.17 \\
0.15 \\
0.12 \\
0.13\end{array}$ & $\begin{array}{l}0.23 \\
0.22 \\
0.21 \\
0.23\end{array}$ & $\begin{array}{l}0.30 \\
0.29 \\
0.27 \\
0.30\end{array}$ & $\begin{array}{l}0.01 \\
0.01 \\
0.01 \\
0.01\end{array}$ \\
\hline PMMA/15 & $\begin{array}{r}2 \\
4 \\
6 \\
8 \\
10\end{array}$ & $\begin{array}{l}33 \\
35 \\
38 \\
44 \\
46\end{array}$ & $\begin{array}{l}0.46 \\
0.35 \\
0.26 \\
0.15 \\
0.12\end{array}$ & $\begin{array}{l}0.31 \\
0.28 \\
0.26 \\
0.23 \\
0.22\end{array}$ & $\begin{array}{l}0.40 \\
0.37 \\
0.34 \\
0.30 \\
0.29\end{array}$ & $\begin{array}{l}0.03 \\
0.03 \\
0.03 \\
0.02 \\
0.02\end{array}$ \\
\hline
\end{tabular}




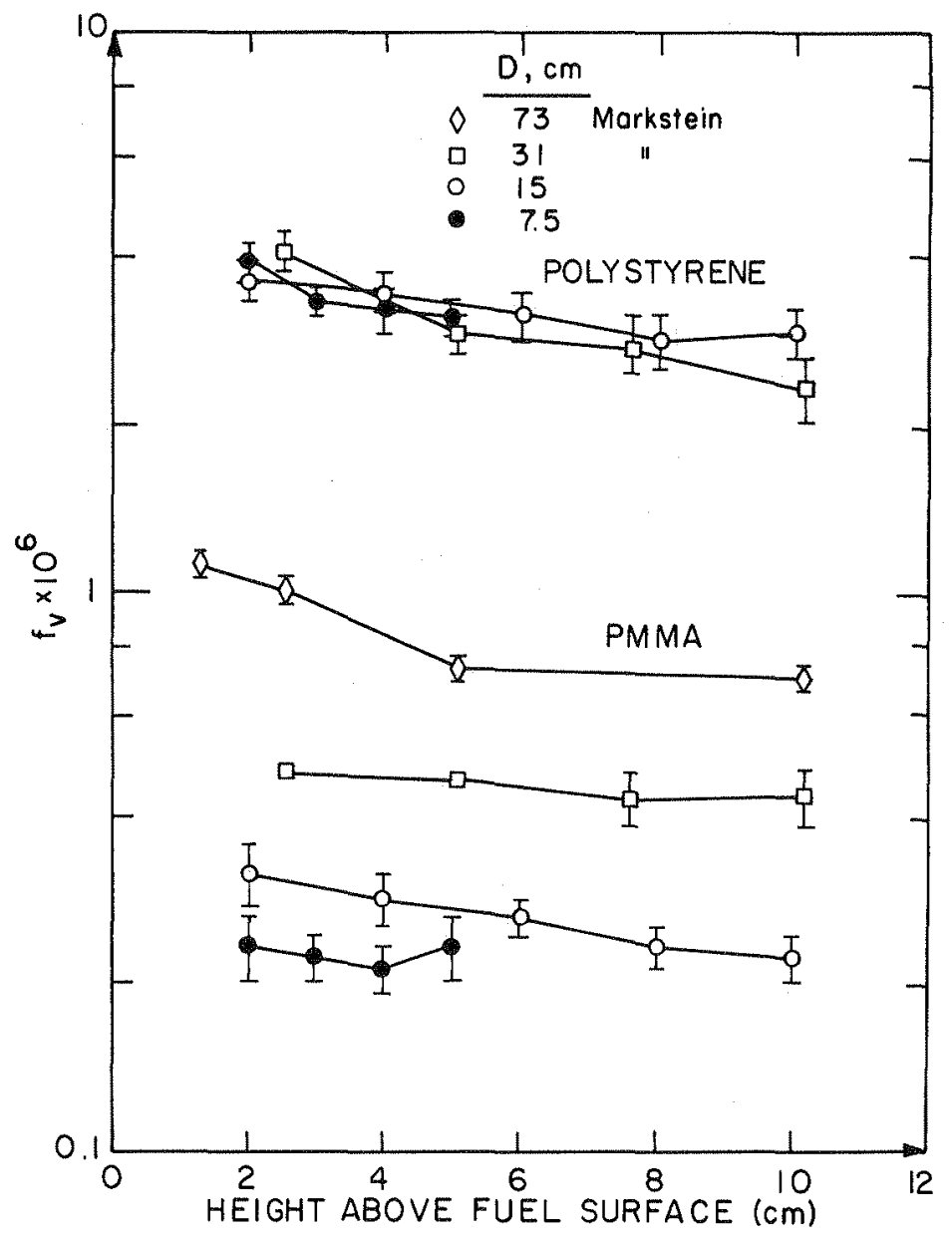

Fig. 3. Carbon particulate volume fraction, $f_{y}$, as a function of height above the fuel surface and flame scale for PS and PMMA. Markstein's values for larger scale flames are from Ref. 12. Contrast the constancy of the optically thick PS with the increase in $f_{y}$ for the optically thin PMMA.

where $V_{f}$ is the flame volume and $A_{f}$ is the flame surface area. However, to a good approximation, the results collapse to

$L \approx D / 2$

where $D$ is the pool diameter. The constancy of $\varepsilon$ for each pool fire in column 6 of Table I supports the uniform $f_{v}$ approximation. Figure 3 combines these data with those of Markstein [12] to display the difference between the optically thick PS and the optically thin PMMA. The PS $f_{V}$ is invariant with scale while the PMMA $f_{y}$ increases by over a factor of 3 , roughly as $D^{1 / 2}$ [19] when the $31 \mathrm{~cm}$ and $75 \mathrm{~cm}$ data are corrected. The soot so dominates the gas in the polystrene flame that no correction of Markstein's Schmidt method data at $31 \mathrm{~cm}$ for $\mathrm{H}_{2} \mathrm{O}$ or $\mathrm{CO}_{2}$ absorption is necessary [19]. Gas absorption or fluorescence has 
been shown [22] not to effect the multi-wavelength laser measurements described here.

Why does $f_{v}$ behave as shown in Fig. 3? Orloff and de Ris [9] have calculated radiative and convective energy fluxes to pool fire fuel surfaces for a wide variety of fuels and diameters. The ratio of radiation to convection is typically thirty. Therefore the fuel pyrolysis rate [21] is controlled by the flame radiation. Table I shows $\varepsilon$ increasing by $200 \%$ for PMMA as D increases from 7.5 to $15 \mathrm{~cm}$. Similar increases occur at larger $D$. So the fuel pyrolysis rate is increasing as the flame radiation, given by $\mathrm{Eq} .(1)$, increases with $\mathrm{D}$ and $\varepsilon$. The increased pyrolysis rate causes the fuel mass fraction at the pool surface, $Y_{f w}$, to approach unity [23]. The literature $[24,25]$ suggests that the soot formation rate is a nearly linear function of $Y_{f}$ and an exponential function of $T_{f}$. Assuming $T_{f}$ stays $\sim 1200^{\circ} \mathrm{K}$, the soot formation rate will increase as the fuel mass fraction profile, $Y_{f}(z)$, increases. Therefore, the $\varepsilon$ increase with optical path, given by Eq. (3), produces an increased surface "q" which in turn increases $Y_{f}$. Through $Y_{f}$, the soot formation rate rises causing $f_{v}$ to increase, hence, the trend shown Fig. 3. Large $f_{v}$ increases occur where $\varepsilon$ is growing rapidly with $D$ and $f_{V}$ remains constant for a given fuel after $Y_{f}$ and $\varepsilon$ become saturated.

This scenario can be quantified by a correlation such as the one shown in Fig. 4. Assume all effects of the fuel chemistry can be accounted for by a

maximum soot volume fraction, $f_{v_{\max }}$. Then seek a correlation of $f_{v} / f_{v_{\max }}$ with $\varepsilon$, or equivalently by $\mathrm{Eq} .(3)$, with $\mathrm{kL}$, the flame optical thickness. The data suggest $f_{v_{\max }}$ of $3.4 \mathrm{ppm}$ for PS and $0.62 \mathrm{ppm}$ for PMMA [19]. These values are

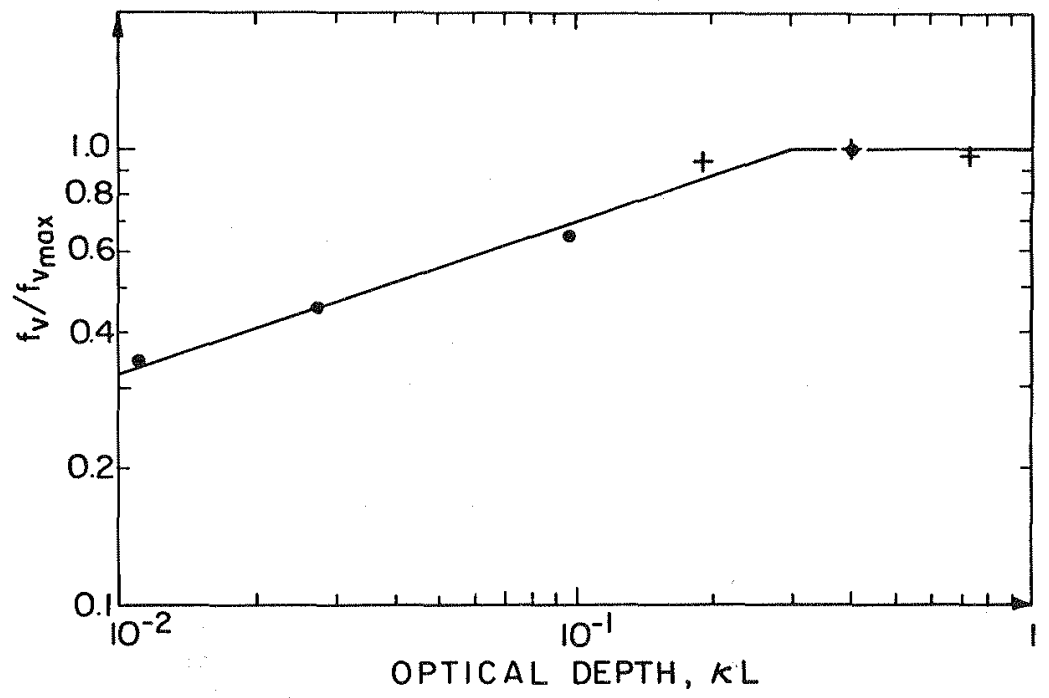

Fig. 4. Proposed correlation of $f_{v}$, normalized on a fuel characteristic, $f_{v_{\max }}$, with optical depth. All pool fires may be described by this simple expression, al though only data for PS $(+)$ and PMMA (c) are avaitable. 
consistant with maxima found in free combusting boundary layer $f_{v}$ profiles [25]. The data in Fig. 4 were plotted using Eq. (11) for $L$ and Eqs. (4 and 5) for $x$. The resulting correlation is

$f_{\mathrm{v}} / f_{v_{\max }}=1.5(K L)^{1 / 3}, \quad k L \leqslant 0.3$,

$f_{\mathrm{v}} / f_{v_{\max }}=1, k L \geqslant 0.3$.

The one third power follows from an optically thin $f_{V} \sim D^{1 / 2}$ with $k \sim f_{V} \sim D^{1 / 2}$ and $L \sim D$, so that $k L$ goes as $f_{V}{ }^{3}$.

Since the data are so sparse, Eq. (12) can only be regarded as speculation. However, it may permit one measurement of $f_{v}$ to provide the $f_{v}$ for all pool fires with that fuel. Six additional fuels $f_{v}{ }^{\prime} s$ at small scale [6] are extrapolated in Table II to illustrate the use of Eq. (12). From Eqs. (4, 5 and 11) with $\mathrm{Tf}_{f} \sim 1200^{\circ}$ and $\mathrm{Fa}_{\mathrm{a}} \sim 0.044$, the small scale soot absorption coefficient and optical depth are calculated as in columns 3 and 4 . Column 5 is $f_{v} / f_{v_{\max }}$ from Eq. (12). Since $f_{v}$ is known, $f_{V_{\max }}$ can be found as in column 6 . With $f_{V_{\max }}$ and $D$, Eqs. $(4,5,11$ and 12$)$ give any other fires' $f_{V}$.

Using $f_{v_{\max }}$ in Eqs. (4 and 5) gives the absorption coefficient in column 7. The pool fire diameter above which $f_{v}=f_{v_{\max }}$, is found from $k \max D_{\max } / 2=0.3$, as in column 8. For common fire fuels, other than PS, $f_{V}=f_{V_{\max }}$ if $D \geqslant 1 / 2 \mathrm{~m}$. The flame emissivity approaches the black limit, $\varepsilon f \rightarrow 1$, for $D \sim 5 D_{\max } \sim 2.5 \mathrm{~m}$ since Eq. (3) gives $1-\exp (-1.5)=0.78$ and gas contributions make up the remainder.

The maximum fuel carbon convertible to soot is estimated in the last column of Table II [26]. Such numbers may be useful in the assessment of the nuclear winter problem. Let $n$ reactions with $\mathrm{CO}_{2}$ as a product occur for each reaction

TABLE II. Uses of the correlation. PS and PP had $D=7.5 \mathrm{~cm}$. All other fuels had $D=15 \mathrm{~cm} . L=D / 2 . \kappa\left(\mathrm{m}^{-1}\right) \approx 1.5 \mathrm{f}_{V}(\mathrm{ppm})$. PU is the Products Research Committee's polyurethane.

\begin{tabular}{|c|c|c|c|c|c|c|c|c|}
\hline Fue 1 & $\begin{array}{l}f_{V} \\
p p m\end{array}$ & $\begin{array}{c}k \\
m^{-1}\end{array}$ & $\kappa L$ & $f_{v} / f_{v}{ }_{\text {max }}$ & $f_{v}{ }_{\text {max }}$ & $\begin{array}{l}\kappa_{\max } \\
m^{-1}\end{array}$ & $\underset{m}{D_{\max }}$ & $\begin{array}{c}\text { Max Soot } \\
\% \text { of } \\
\text { Fuel } c\end{array}$ \\
\hline PS & 3.3 & 4.8 & 0.181 & 0.85 & 3.9 & 5.6 & 0.1 & 20.8 \\
\hline Octane & 0.46 & 0.67 & 0.050 & 0.52 & 0.83 & 1.3 & 0.5 & 6.3 \\
\hline$P U, G M-21$ & 0.51 & 0.75 & 0.056 & 0.57 & 0.89 & 1.3 & 0.5 & 5.7 \\
\hline$P P$ & 0.27 & 0.39 & 0.015 & 0.30 & 0.73 & 1.3 & 0.5 & 5.4 \\
\hline PMMA & 0.22 & 0.32 & 0.012 & 0.34 & 0.65 & 0.94 & 0.6 & 4.0 \\
\hline Wood & 0.29 & 0.42 & 0.031 & 0.45 & 0.62 & 0.93 & 0.6 & 3.5 \\
\hline Acetone & 0.11 & 0.16 & 0.012 & 0.34 & 0.32 & 0.47 & 1.3 & 2.2 \\
\hline Ethanol & 0.07 & 0.10 & 0.008 & 0.30 & 0.24 & 0.33 & 1.8 & 1.9 \\
\hline
\end{tabular}


with $C$ (soot) as a product. Then $1 /(n+1)$ is the fraction of the fuel carbon converted to soot. $n$ is found by equating the measured soot mass per mass of gas product, $Y_{s}$, to a chemical $Y_{s}$. The solid soot density is assumed [25] to be $\rho \sim 1.2 \mathrm{gm} / \mathrm{cm}^{3}$ and the product gas density at 1 atm and $1200^{\circ} \mathrm{K}$ is $\rho \mathrm{g} \sim 0.3 \times$ $10^{-3} \mathrm{gm} / \mathrm{cm}^{3}$. Therefore the measured $Y_{s}=f_{v} \rho / \rho \mathrm{g} \sim 4 \times 10^{3} \mathrm{fv}$. In the $\mathrm{CO}_{2}$ producing reaction let $\mathrm{M}_{\mathrm{g}}$ be the product mass. In the $\mathrm{C}$ producing reaction let $M_{\mathrm{gc}}$ be the gas product mass and $M_{S}$ be the solid product mass. Then the chemicâl $Y_{s}=M_{s} /\left(n M_{g}+M_{g c}\right)$. Equating $Y_{s}^{\prime} s$ and solving for $n$ gives

$\max$ soot/fuel carbon $=(n+1)-1=M_{g} /\left(2.5 \times 10^{-4} M_{s} / f_{v_{\max }}+M_{g}-M_{g c}\right)$

For example, polypropylene, $P P$, is $\mathrm{C}_{3} \mathrm{H}_{6}$ which, with $4 \mathrm{~N}_{2}$ per $\mathrm{O}_{2}$ for air, gives $M_{g}=690, M_{g c}=222$ and $M_{s}=36$. From Table II, $f_{v_{\max }}=0.73 \times 10^{-6}$, so $n=$ 17.6 and $\mathrm{Eq}$. (13) gives $5.4 \%$ of the fuel carbon as the maximum convertible to soot. These values are in good agreement with de Ris's estimates [1] of $18 \%$ for PS, $5.5 \%$ for PP and $1.9 \%$ for PMMA.

\section{CONCLUISIONS}

1. Within pool fires the vertical line of sight averaged soot volume fraction decreases sufficiently slowly with height to be approximated as constant throughout the flame.

2. Limited measurements suggest, that for a given fuel, $f_{V}$ is only a function of the optical depth of the pool fire flame, i.e.,

$$
f_{v} / f_{v_{\max }} \approx 1.5(k L)^{0.33} \text { for } k L \leqslant 0.3 \text { and } f_{v}=f_{v_{\max }} \text { for } k L \geqslant 0.3 \text {. }
$$

\section{REFERENCES}

1. de Ris, J., "Fire Radiation - A Review," Seventeenth Symposium (International) on Combustion, The Combustion Institute, 1003, 1979.

2. Emmons, H.W., "The Calculation of a Fire in a Large Building," 20th Joint ASME/AIChE National Heat Transfer Conference, Paper 81-HT-2, Aug. 1981.

3. Pagni, P.J., and Bard, S., "Particulate Volume Fractions in Diffusion Flames," Seventeenth Symposium (International) on Combustion, The Combustion Institute, 1017, 1979.

4. Tien, C.L., and Lee, S.C., "Flame Radiation," Prog. Energy Combust. Sci., 8 , $41,1982$.

5. Yuen, W.W., and Tien, C.L., "A Simple Calculation Scheme for the Luminous-Flame Emissivity," Sixteenth Symposium (International) on Combustion, The Combustion Institute, 1481, 1977.

6. Bard, S., and Pagni, P.J., "Carbon Particulate in Small Pool Fire Flames," ASME J. Heat Transfer, 103, 2, 357, 1981.

7. Modak, A.T., "Thermal Radiation from Pool Fires," Combust. Flame, 29, 177, 1977.

8. Hubbard, G.L., and Tien, C.L., "Infrared Mean Absorption Coefficients for Luminous Flames and Smoke," ASME J. Heat Transfer, 100, 235, 1978. 
9. Orloff, L., and de Ris, J., "Froude Modeling of Pool Fires," Nineteenth Symposium (International) on Combustion, The Combustion Institute, 885 , 1983.

10. Orloff, L., "Simplified Radiation Modeling of Pool Fires," Eighteenth Symposium (International) on Combustion, The Combustion Institute, 549, 1981 .

11. Lee, S.C., and Tien, C.L., "Optical Constants of Soot in Hydrocarbon Flames," Eighteenth Symposium (International) on Combustion, The Combustion Institute, 1159, 1981 .

12. Markstein, G.H., "Radiative Properties of Plastic Fires," Seventeenth Symposium (International) on Combustion, The Combustion Institute, 1053, 1979.

13. Markstein, G.H., "Measurements on Gaseous - Fuel Pool Fires with a Fiber-Optic Absorption Probe," Combust. Sci. and Tech., 39, 215, 1984.

14. Santoro, R.J., Semerjian, H.G., and Dobbins, R.A., "Soot Particle Measurements in Diffusion Flames," Combust. Flame, 51, 2, 203, 1983.

15. Dobbins, R.A., and Mulholland, G.W., "Interpretation of Optical Measurements of Flame Generated Particles," Combust. Sci. Tech., 40, 175, 1984.

16. Shinotake, A., Koda, S., and Akita, K., "An Experimental Study of Radiative Properties of Pool Fires of an Intermediate Scale," Combust. Sci. Tech., 43, $85,1985$.

17. Lee, S.C., Yu, Q.Z., and Tien, C.L., "Radiative Properties of Soot from Diffusion Flames," J. Quant. Spect. Radiat. Transfer, 27, 387, 1982.

18. Markstein, G.H., "Scanning-Radiometer Measurements of the Radiance Distribution in PMMA Pool Fires," Eighteenth Symposium (International) on Combustion, The Combustion Institute, 537, 1981.

19. Brosmer, M., Private Communication.

20. Zukoski, E.E., "Fluid Dynamic Aspects of Room Fires," Plenary Lecture, this Symposium.

21. Modak, A.T., and Croce, P.A., "Plastic Pool Fires," Combust. Flame, 30, 251, 1977.

22. Bard, S., and Pagni, P.J., "Comparison of Laser-Induced Fluorescence and Scattering in Pool-Fire Diffusion Flames," J. Quant. Spect. Radiat. Transfer, 25, 453, 1981 .

23. Pagni, P.J., "Diffusion Flame Analyses," Fire Safety J., 3, 273, 1981.

24. Glassman, I., and Yaccarino, P., "Temperature Effect in Sooting Diffusion Flames," Eighteenth Symposium (International) on Combustion, The Combustion Institute, 1175,1981 .

25. Pagni, P.J., and Okoh, C.I., "Soot Generation within Radiating Diffusion Flames," Twentieth Symposium (International) on Combustion, The Combustion Institute, 1045,1985 .

26. Rockett, J.A., private communication. 
